\title{
Gratitude \& self esteem among college students
}

\begin{abstract}
The study was conducted to conceptualize and find relationship between self-esteem and gratitude among college students. Data was collected through Rosenberg self-esteem scale and gratitude GQ6 questionnaire. 60 students from both genders were administered both questionnaires. The finding revealed that there was no significant relationship between selfesteem and gratitude. At the end, gender differences were analyzed by using t, test. There was no significant difference among male and female students regarding self esteem and gratitude.
\end{abstract}

Keywords: Self-esteem, Gratitude, Rosenberg Scale, Gratitude scale

\author{
Volume 9 Issue 4 - 2018
}

\author{
Asif Amin, Zaman Khalid, Muhammad \\ Zeeshan Ashraf, Hira Khan, Shumaila Pervaiz \\ Department of Psychology, Virtual University of Pakistan, \\ Pakistan
}

Correspondence: Asif Amin, Department of Psychology, Virtual University of Pakistan, Gali mandar wali ward \#3 house \# 0 Baddomalhi district Narowal, Punjab Pakistan, Tel +923320458880, Email asifamin@outlook.com

Received: June 28, 2016 | Published: July 16, 2018

\section{Introduction}

With the foundation of positive psychology, gratitude has gain to much courtesy among the psychologist and theorist from social, development. ${ }^{1}$ Gratitude defined as state of attributes, in literature and different religions define gratitude in different views. (Chen and Kee, 2008, Emmons 2003, Watkin 2003) Gratitude is the gratefulness, when a someone does good something for any one then feels grateful. Gratitude is defined as, as "a sense of thankfulness and joy in response to receiving a gift, whether the gift be a perceptible benefit form a specific other or a moment of peaceful ecstasy suggested by natural beauty". ${ }^{2}$ Self-esteem, one's over-all sense of his or her worth or value. ${ }^{3}$ May be theorized to act as a mediator of the connection. Considered gratitude had relation with self-esteem. The main purpose of this research was to find the relation of self-esteem with gratitude, Self-esteem is the main part of modern life, it is seen as a key role to success, in financial life, social life, mental health and personal fulfilment, and it regarded as an medicine or treatment to underachievement, drug abuse and crime, street crime (Branden, 1994; Mecca, Smelser, \& Vasconcellos, 1989. Lot of studies showed that self-esteem is related and have the relation with confidence, nonblaming behavior, self-care, love and independent and cooperative in life.

The views of gratitude got attraction in popular culture. The pervasiveness of book targeted to general audiences on the topic. (Steindler Rast 1984, Van Kaam \& Muto 1993, Miller 1995, Breathnach 1996, The concept of gratitude recently has attracted considerable inesest in the popular culture. The prevalence of books targeted to general audiences on the topic (Breathnach, 1996; Hay, 1996; Miller 1995; Ryan 1999; Steindler Rast, 1984; Tuner, 1998; Van Kaam\& Muto, 1993) state to the comprehensive plea of this eternal concept. Gratitude is derived from the Latin Gratia, meaning grace, graciousness or gratefulness. In the root of Latin, "have to do with kindness, generousness, gift the beauty of giving and receiving or getting something for nothing" ( Pruyser, 1976, p.69). As a psychological, religion and socially gratitude had same meaning, all of these, appreciate gratitude and in all of eras kindness is appreciated.

\section{Literature review}

Literature review showed that gratitude is connected with strongly life satisfaction but the level to which overriding variables facilitate their relationship is comparatively not much studies. ${ }^{4}$ Literature review has predictable one hopeful mediator among gratitude and life satisfaction is communal support. Like other positive emotion, gratitude is believed to reflect motivate and reinforce social action in both the giver and gift recipient (Fred-Rickson). So, gratitude can build from social support of members of community. Some theorist has further proclaimed that, gratitude might have relation with selfesteem and some them claimed that person which have higher level of gratitude are better to perceive, and appreciate social support from members of society. ${ }^{1,5}$ "Build and Broaden" model presented that, positive or cheer full emotions, and gratefulness and broaden people produced better behaviors and build enduring personal resource. Fred-Rickson's 2001Gratitude enhance the level of self-esteem, confidence, moral, ethics, some theorist has said that, persons which has gratefulness behavior or gratitude have higher levels of self-esteem and self-measurement and skill greater comfort. ${ }^{1}$ Lot of experimental studies shown, people which are at higher level of gratitude has their self-esteem at highest level ${ }^{6}$ Furthermore, self-esteem hypothetically (e.g. Hermans 1992; Mack 1983) And practically (e.g. 7; b; Sedikides et al. 2004). Showed and has contribution to satisfaction of life so gratitude associated with self-esteem's higher level. Long history in philosophy, psychology and sociology, different researchers examined the relation of gratitude with different aspects, and lot of studies on how to improve gratitude level, and many studies showed up, relation of gratitude with social support, life satisfaction and self-esteem. Experimental works has given results that social support as an element of self-esteem. (Rosenberg 1979 Mruk 1995 give theoretical work on social support as an element of self-esteem. Abundantly theoretical studies shown that, social support have relation and predicted person's self-esteem level. Kong et al. ${ }^{7}$ Many studies showed up results, gratitude believed, has relation with motivation, self-analysis, selfesteem, reinforcement and social action in both aspects, giver and gift receivers (2004 Fred Rickson. Gratitude easily builds social life, and got social support from society. Some theorist has further examined that person has highest level of gratitude, is more convenient, better perceiver, and appreciative from others, so that's why got highest place in society and experience better moral person ${ }^{1,5}$ Abundant studies have established that self-esteem is contrariwise associated to depression in western samples ${ }^{3}$ and optimistic connected to indicators of subjective comfort in numerous cultures (Lucas et al. 1996).

\section{Significance of the study}

Up to this moment, nationally very few studies have been found to determine and identify the correlation between self-esteem and 
gratitude. The outcomes of this research project will helpful for the Pakistani society especially for the students will know about the link between self-esteem and gratitude. When there will be greater awareness, this will help the students to know about the solutions of the problems. The result of this research will contribute to enhance level of gratitude and self-esteem.

\section{Objective}

Following are the main objective of this research

1. To find out There is a relationship between perceived self-esteem and gratitude among college students

2. To find the difference between female's self-esteem had relation with gratitude and male's self-esteem had relation with gratitude.

\section{Hypothesis}

There is a relationship between perceived self-esteem and gratitude among college students.

Male and female college students differ in terms of self-esteem.

Male and female college students differ in terms of gratitude.

\section{Methodology}

\section{Research methodology}

The current study utilized correlational design to determine the extent to gratitude related to self-esteem among college students. Correlation project was considered to be a type of non-experimental research in which the main objective was to collect evidence to support link between two of and more naturally occurring variables.

This project was a quantitative research and questionnaire was used to measure the self-esteem and gratitude. Self-esteem questionnaire consisted on ten question and Gratitude scale consisted on six questions

\section{Data collection tools}

For the purpose of data collection two questionnaires was used and collected data about self-esteem and gratitude:

1. Rosenberg self-esteem scale

2. Gratitude questionnaire GQ6

\section{Rosenberg self-esteem scale}

A 10-item scales that measures global self-worth by measuring both positive and negative feelings about the self. The scale is believed to be uni-dimensional. All items are answered using a 5-point Likert scale format ranging from strongly agree to strongly disagree.

Strongly agree $=1$, agree $=2$, neutral $=3$ disagree $=4$ strongly disagree $=5$

\section{Gratitude scale GQ6}

Gratitude scale is six item scale which measure gratitude all the item are answered using a 5 point Likert scale format ranging from strongly agree to strongly disagree.

Strongly agree $=1$, agree $=2$, neutral $=3$ disagree $=4$ strongly disagree $=5$

\section{Target population}

Target population consisted of college students from the rural area of Narowal Punjab. Student was subject wise some was Science students and some was arts students unit of analysis in this project was individual. Data was collected from students individually.

Sample size

Sample size was consisted of 60 students from College, in which 30 were girls and 30 boys

$\mathrm{N}=60$

Age Range

The age of population was range of $18-21$

\section{Sampling technique}

Convenience sampling technique will be used in this project. Convenience sampling is a specific type of non-probability sampling method, which depends on data collection form population who are suitably available to contribute in project. The convenience sample will be used in this project because of its ease and cost effective.

\section{Data collection}

A multi question questionnaire was used to administer to participants in college. All the questionnaire administrates was in English language and simple wording. And used convenience sampling method, Firstly, brief introduced to students about research, and explained briefly about the questionnaire, then both questionnaire filled by students, all the data kept confidential and assured. Almost $15-2 \mathrm{O}$ min took students to fill up questionnaire.

\section{Data processing \& analysis}

All the result analyzed with the help of SPSS (IBM version 24.O) package. First a correlation analysis was conducted to examine the link of self-esteem and gratitude and then t-test analysis is carried out to see difference experience of male and female regarding to selfesteem and gratitude.

\section{Data analysis}

Table 1 shows the descriptive statics of study variables. i.e Mean and standard deviation for each variable that was measured by selfesteem and gratitude. Gratitude had highest standard deviation of $(\mathrm{SD}=4.13693)$ and self-esteem had standard deviation of $\mathrm{SD}=2.63$ this mean that self-esteem was less varied.

Table I Descriptive statistics of the study variable (self esteem and gratitude)

\begin{tabular}{lccclcll}
\hline \multicolumn{7}{c}{ Range } \\
\hline & N & Mean & S.D & Potential & Actual & Skewness & Kurtosis \\
\hline $\begin{array}{l}\text { Self } \\
\text { esteem }\end{array}$ & 60 & 36.6 & 2.6 & $10-50$ & $13-43$ & -1.55 & 0.9 \\
$\begin{array}{l}\text { Self } \\
\text { concept }\end{array}$ & 60 & 22.04 & 4.1 & $6-30$ & $16-27$ & -1.21 & 1.2 \\
\hline
\end{tabular}

Table 2 shows correlation analysis was carried out using Statistical package for social sciences (SPSS). A Pearson correlation coefficient was computed to assess the relationship between Self Esteem and Self Gratitude. There was no significant relationship between self esteem and Gratitude, i.e. $\mathrm{r}(58)=0.20, \mathrm{n}=60, \mathrm{p}=0.88$. A t-test was computed 
to find the gender differences between the study variables. Table 3 shows t-test analysis based on gender, male and female students. No significant difference was found among male and female students in terms of Self esteem, $\mathrm{t}(58)=-0.13, \mathrm{p}=0.89$ and Gratitude $\mathrm{t}(58)=-1.60$, $\mathrm{p}=0.11$.

Table 2 Correlation matrix of the variables (self esteem and gratitude)

\begin{tabular}{lll}
\hline Variables & Self esteem & Gratitude \\
\hline Self Esteem & $\mathrm{I}$ & 0.2 \\
Gratitude & - & $\mathrm{I}$ \\
\hline
\end{tabular}

$*_{p}<0.05, * * p<0.001$

Table 3 Mean, standard deviation, $t$ and $p$ value of male and female students

\begin{tabular}{|c|c|c|c|c|c|c|c|c|}
\hline \multirow{2}{*}{ Variable } & \multicolumn{2}{|c|}{ Males } & \multicolumn{2}{|c|}{ Females } & \multirow{2}{*}{$t(d f)$} & \multirow{2}{*}{$\mathbf{p}$} & \multicolumn{2}{|c|}{$95 \% \mathrm{Cl}$} \\
\hline & $M$ & SD & $\mathbf{M}$ & SD & & & $\begin{array}{l}\mathrm{LL} \\
\mathrm{UL}\end{array}$ & \\
\hline $\begin{array}{l}\text { Self } \\
\text { esteem }\end{array}$ & 36.6 & 2.9 & 36.7 & 2.27 & $-0.13(58)$ & 0.89 & -1.4 & 1.2 \\
\hline Gratitude & 21.2 & 4.4 & 22.9 & 3.65 & $-1.60(58)$ & 0.11 & -3.7 & 0.41 \\
\hline
\end{tabular}

\section{Discussion}

Research intended to check relation among gratitude and selfesteem among students of college in Pakistan. These was the hypothesis of the current work

1. There is a relationship between perceived self-esteem and gratitude among college students.

2. Male and female college students differ in terms of self-esteem.

3. Male and female college students differ in terms of gratitude.

As expected that self-esteem has positive relation with gratitude among college students and thought that student had higher level of self-esteem had highest level of gratitude.

But the results of this study did not support above hypothesis, self-esteem has not much significant relation with gratitude, one clue might help to explain results that gratitude has positive relation with self-esteem.

\section{Gratitude $\rightarrow$ Self-esteem}

Numerous studies have shown that grateful people are likely to perceive greater social support from others. ${ }^{5}$ Those people of society perceive more social support have the higher level of self-esteem. (Kong and You 2013) It was also indicated that females were more grateful then man, this is in harmony with prior research works that report females had got high score than man on test gratitude. ${ }^{5}$ This is possibly because male consider the involvement and appearance of gratitude as evidence of susceptibility and softness, which may threaten their maleness and communal status (Levant and Kopecky 1995). Current research work was to find out the relation of selfesteem and gratitude among the Pakistani college students. A very little relationship was found that was non-significant in both variables. The same results were found in a study with correlation of 0.3 in a Chinese study ${ }^{8}$ Lot of experimental studies shown, people which are at higher level of gratitude has their self-esteem at highest in this work, we have find that female is more grateful then man, but this difference is not so much significant that say that female is more grateful then man. this is in accordance with previous studies that report female had higher scores than male on test of gratitude (Chen 2013; Froh et al. 2009; Kashdan et al. 2009) There are many other factors which have connection with gratitude, like satisfaction of life, wellbeing, and social support several limitations which have the effect on this research work, the 1st limitation is, study was cross sectional design, in this kind of design chronological order of the variable, dependent variable did not be verified. ${ }^{9}$ Longitudinal studies would be desired in order to draw any results about the interconnection or directionality of the associations between gratitude, self-esteem. $2^{\text {nd }}$ limitation data which gathered depended on self-report. $3^{\text {rd }}$ limitation, limited area of population. The current finding reflects cultural difference and difference of social class status, so future research used cross-cultural population to find the correct answer. The farming of gratitude may be work as a precautionary therapy to help person to enhance their wellbeing in future. It also works as active therapy, gain support from socially and from other members of society and so that enhance selfesteem level. Furthermore, although not so much substantial difference in final model was found, the gender variance in some structural path suggest that different types of positive psychology involvements for gratitude among males or females may be considered for use in psychology service.

\section{Summary}

Study was conducted to find the relation of self esteem with gratitude among the college students data were collected from 60 students from college. Data was collected according to psychological ethics and convenience sampling technique was used. And analysis was carried out by using SPSS software package. Determinant of self esteem and gratitude, showed that by statistical data view showed negative relation, self esteem have not much effect on person gratitude.

\section{Conclusion}

From the finding of this study, following conclusions may be drawn regarding students self esteem and gratitude. Study showed that, gratitude did not have significant relation with self esteem among students of college. ${ }^{10-13}$

\section{Recommendations}

This study should be on large level and conducted in different colleges and universities for additional research in these field Private colleges and govt. colleges give equal environment to students. With teaching also give the lectures about ethics and morels duties of human being.

\section{Limitation}

1. The results of this research cannot be generalized to whole Pakistan because of the sample size.

2. The research was conducted in limited area

3. Social class was not considered while recording responses.

4. Questionnaire was used in English Language, which may create some misunderstanding due to difficult terms.

5. The respondent could not be measure on important variable like, marital status, home status, social class, middle class, and upper class.

\section{Acknowledgements}

In the name of Almighty Allah, the most merciful, who blessed me 
on each and every occasion in my life, I feel so blessed that Almighty Allah gives me courage and enthusiasm to complete this project in such a nice way. I feel so humbled that Almighty Allah has given me the power and courage to overcome all the hurdles which I have to face during my whole degree program.

I am grateful to all my friends and acquaintances that help me in completing my project. I want to thank Mr. Zaman, Dr Neda, Miss Hira khan, Miss Andrea,Ms. Amtur-Rehman Fatima, Ms. Maryam Muhammad Akram, Ms. Saba Rashid Ahmed and Ms. Taranum Hayat. I am thankful to Amna Ali shakar, and Zaman for providing and helping in the Statistical Package for Social Sciences (SPSS).

Here I especially want to thank my Project supervisor Ms. ASMA ZAFAR who helped me a lot in my every minor issue even I asked every bit that confused and she tried to satisfy me in every possible way.

I also want to give my especial thanks to "VIRTUALUNIVERSITY OF PAKISTAN" which gave me valued and noble education, in a place where there was no opportunity to get education, in the rural areas of Sindh. I am feeling so lucky to be a student of this precious university and with knowledge; this institution teaches me a lot more things than my expectation.

Lastly, I am grateful to my colleagues and Commander of who always help to adjust my Job duties and motivate me. I am thankful to them for their constant encouragement and support without which this report would not be possible.

At the last I will again pay thanks to all those persons and Virtual University of Pakistan.

May Allah bless and give them prosperity ever.

\section{Conflict of interest}

None.

\section{References}

1. McCullough ME, Emmons RA, Tsang J. The grateful disposition: A conceptual and empirical topography. $J$ Pers Soc Psychol. 2002;82:112-127.
2. Emmons RA. The Psychology of Gratitude: An introduction. In: Emmons RA, McCullough ME, editiors, The Psychology of Gratitude. New York, NY: Oxford University Press. 2004;3-16.

3. Rosenberg M. Society and the adolescent self-image. Princeton, $N J$ : Princeton University Press. 1965;148(3671):804.

4. Wood AM, Froh JJ, Geraghy AW. Gratitude and well-being: A review and theoretical integration. Clinical psychology review. 2010;30:890-905.

5. Wood AM, Maltby J, Gillett R, et al. The role of gratitude in the development of social support, stress, and depression: Two longitudinal studies. Journal of Research in Personality. 2008;42(4):854-871.

6. Li D, Zhang W, Li X, et al. Gratitude and suicidal ideation and suicide attempts among Chinese Adolescents: Direct, mediated, and moderated effects. J Adolesc. 2012;35(1):55-66.

7. Zhao J, Kong F, Wang Y. Self-esteem and humor style as mediators of the effects of shyness on loneliness among Chinese college students. Personality and Individual Differences. 2012;52(6):686-690.

8. Layous K, Chancellor J, Lyubomirsky S. Positive activities as protective factors against mental health conditions. J Abnorm Psychol. 2014;123(1):3-12.

9. Maxwell SE, Cole DA. Bias in cross-sectional analyses of longitudinal mediation. Psychol Methods. 2007;12(1):23-44.

10. Emmons RA. THANKS! How the New Science of Gratitude Can Make You Happier. New York, NY: Houghton Mifflin Company. Houghton Mifflin Harcourt; 2007.

11. Toussaint L, Friedman P. Forgiveness, gratitude, and well-being: The mediating role of affectand beliefs. Journal of Happiness Studies. 2009;10;635-654.

12. Wood AM, Joseph S, Maltby J. Gratitude predicts psychological wellbeing above the Big Five facets. Personality and Individual Differences. 2009; 46:443-447.

13. Yarcheski A, Mahon NE, Yarcheski TJ. Social support and well-being in early adolescents: The role of mediating variables. Clinical Nursing Research. 2001;10(2):163-181. 


\section{Appendix}

\section{Appendix A: Rosenberg Self-esteem Scale}

\section{ROSENBERG SELF-ESTEEM SCALE}

Rosenberg M (1965) Society and the adolescent self-image. Princeton, NJ: Princeton University Press.

A 10-item scale that measures global self-worth by measuring both positive and negative feelings about the self. The scale is believed to be uni-dimensional. All items are answered using a 4-point Likert scale format ranging from strongly agree to strongly disagree.

Scale: Please paste this questionnaire in appendices.

\section{Instructions}

Below is a list of statements dealing with your general feelings about yourself. Please indicate how strongly you agree or disagree with each statement.

1. On the whole, I am satisfied with myself.

Strongly Agree Agree Disagree Strongly Disagree

2. At times I think I am no good at all.

Strongly Agree Agree Disagree Strongly Disagree

3. I feel that I have a number of good qualities.

Strongly Agree Agree Disagree Strongly Disagree

4. I am able to do things as well as most other people.

Strongly Agree Agree Disagree Strongly Disagree

5. I feel I do not have much to be proud of.

Strongly Agree Agree Disagree Strongly Disagree

6. I certainly feel useless at times.

Strongly Agreen Agree Disagree Strongly Disagree

7. I feel that I'm a person of worth, at least on an equal plane with others.

Strongly Agree Agree Disagree Strongly Disagree

8. I wish I could have more respect for myself.

Strongly Agree Agree Disagree Strongly Disagree

9. All in all, I am inclined to feel that I am a failure.

Strongly Agree Agree Disagree Strongly Disagree

10. I take a positive attitude toward myself.

Strongly Agree Agree Disagree Strongly Disagree

\section{Scoring:}

Items 2, 5, 6, 8, 9 are reverse scored. Give "Strongly Disagree" 1 point, "Disagree" 2 points, "Agree" 3 points, and "Strongly Agree" 4 points. Sum scores for all ten items. Keep scores on a continuous scale. Higher scores indicate higher self-esteem.

\section{Appendix B: Gratitude Questionnaire-6 (GQ-6)}

\section{The Gratitude Questionnaire-Six Item Form (GQ-6)}

Using the scale below as a guide, write a number beside each statement to indicate how much you agree with it.

$1=$ strongly disagree

$2=$ disagree

3 = slightly disagree

$4=$ neutral

5 = slightly agree

6 = agree

7 = strongly agree

1. I have so much in life to be thankful for.

2. If I had to list everything that I felt grateful for, it would be a very long list.

3. When I look at the world, I don't see much to be grateful for.*

4. I am grateful to a wide variety of people.

5. As I get older I find myself more able to appreciate the people, events, and situations that have been part of my life history.

6. Long amounts of time can go by before I feel grateful to something or someone.*

\section{Scoring Instructions:}

1. Add up your scores for items 1, 2, 4, and 5 .

2. Reverse your scores for items 3 and 6 . That is, if you scored a "7," give yourself a "1," if you scored a "6," give yourself a " 2, ," etc.

3. Add the reversed scores for items 3 and 6 to the total from Step I.This is your total GQ-6 score.This number should be between 6 and 42. 